\title{
NICU Bedside Caregivers Sustain Process Improvement and Decrease Incidence of Bronchopulmonary Dysplasia in Infants $<30$ Weeks Gestation
}

\author{
Sara J Mola MD, David J Annibale MD, Carol L Wagner MD, \\ Thomas C Hulsey ScD, and Sarah N Taylor MD
}

\begin{abstract}
BACKGROUND: The objective of this study was to investigate whether a respiratory care bundle, implemented through participation in the Vermont Oxford Network-sponsored Neonatal Intensive Care Quality Improvement Collaborative (NIC/Q 2005) and primarily dependent on bedside caregivers, resulted in sustained decrease in the incidence of bronchopulmonary dysplasia (BPD) in infants < 30 wk gestation. METHODS: A retrospective cohort study was conducted. Infants inborn between 23 wk and 29 wk +6 d of gestation were included. Patients with congenital heart disease, significant congenital or lung anomalies, or death before intubation were excluded. Four time periods (T1-T4) were identified: T1: September 1, 2002 to August 31, 2004; T2: September 1, 2004 to August 31, 2006; T3: September 1, 2006 to August 31, 2008; T4: September 1, 2008 to August 31, 2010. RESULTS: A total of 1,050 infants were included in the study. BPD decreased significantly in $\mathrm{T} 3$ post-implementation of the respiratory bundle compared with $\mathrm{T} 1(29.9 \%$ vs $51.2 \%$, respectively; adjusted odds ratio [aOR] $=0.06[95 \%$ CI 0.03-0.13], $P=<.001)$. The decrease was not sustained into T4. There was a significant increase in the rate of BPD-free survival to discharge in T3 compared with $\mathrm{T} 1(53.1 \%$ vs $47 \%$; aOR $=1.68$ [95\% CI 1.11-2.56], $P=.01)$ that was also not sustained. The rate of infants requiring $\mathrm{O}_{2}$ at $28 \mathrm{~d}$ of life decreased significantly in T3 versus T1 (40.3\% vs 69.9\%, respectively; aOR $=0.12$ [95\% CI 0.07-0.20], $P=<.001)$. Increases in the rate of surfactant administration by $1 \mathrm{~h}$ of life and rate of caffeine use were observed in T4 versus T1, respectively. There was a significant decrease in median ventilator days and a significant increase in the median number of noninvasive CPAP days throughout the study period. CONCLUSIONS: In this study, implementation of a respiratory bundle managed primarily by nurses and respiratory therapists was successful in increasing the use of less invasive respiratory support in a consistent manner among very low birthweight infants at a single institution. However, this study and others have failed to show sustained improvement in the incidence of BPD despite sustained process change. Key words: bronchopulmonary dysplasia; very low birthweight; prematurity; mechanical ventilation; bedside caregiver; NICU. [Respir Care 2015;60(3):309-320. (C) 2015 Daedalus Enterprises]
\end{abstract}

Introduction

With the advent of antenatal steroids, surfactant replacement therapy, and improved ventilatory and nutritional

Dr Mola is affiliated with the Department of Pediatrics, Division of Neonatology, University of Maryland School of Medicine, Baltimore, Maryland; Drs Annibale, Wagner, and Taylor are affiliated with the Department of Pediatrics, Division of Neonatal-Perinatal Medicine, Medical University of South Carolina, College of Medicine, Charleston, South Carolina; Dr Hulsey is affiliated with the Department of Pediatrics, Med- strategies, there has been an increase in the survival of very low birthweight (VLBW) infants. However, little improvement in the incidence of bronchopulmonary dysplasia (BPD) has been appreciated. ${ }^{1}$ Barotrauma, volutrauma,

\footnotetext{
ical University of South Carolina College of Medicine, Charleston, South Carolina.

The authors have disclosed no conflicts of interest.

Supplementary material related to this paper is available at http:// www.rcjournal.com.
} 


\section{NICU Bedside Caregivers Decrease BPD}

and oxygen toxicity have been recognized as significant contributors to the development of BPD in VLBW infants. ${ }^{2} \mathrm{~A}$ reduction in the incidence of BPD in VLBW infants has been noted after the implementation of respiratory care quality improvement initiatives at other institutions. ${ }^{3-5}$

See the Related Editorial on Page 469

From 2002-2003, a single 66-bed tertiary level neonatal intensive care center demonstrated a BPD rate in the highest quartile when compared with Vermont Oxford Network (VON) centers similar in size and acuity. In conjunction with the VON-sponsored Neonatal Intensive Care Quality Improvement Collaborative (NIC/Q 2005) with focus on respiratory care (Tender Lung Care [TLC]), a multidisciplinary group at this institution developed and implemented evidence-based improvements to increase noninvasive respiratory support and decrease oxygen exposure. The resulting respiratory care bundle was designed to integrate and standardize individual clinical interventions such as prophylactic surfactant administration, methylxanthine use, lower oxygen saturation targeting, and functional residual capacity preservation through post-extubation CPAP. The implementation of these interventions relied heavily upon bedside caregivers (ie, nurses and respiratory therapists) for consistency and sustainability, while physicians and neonatal nurse practitioners provided procedural and pharmacologic support.

The objective of this study was to investigate whether quality improvements implemented through participation in the TLC group of the VON-sponsored NIC/Q 2005 and primarily dependent on bedside caregiver modifications resulted in a sustained decrease in the incidence of BPD in infants $<30 \mathrm{wk}$ gestation at a single tertiary care facility.

\section{Methods}

The pathogenesis of BPD is multifactorial, and quality improvement efforts to decrease BPD typically use a bundle of interventions together. Each practice in the bundle may have varying levels of evidence, and the practices are often referred to as potentially better practices in neonatalogy. ${ }^{6}$ In conjunction with the VON-sponsored NIC/Q TLC group (2005-2006), the participants from Medical University of South Carolina were charged with exploring the evidence for minimizing airway inflammation and oxygen toxicity. The group identified potentially better

Correspondence: Sara J Mola MD, Department of Pediatrics, Division of Neonatology, University of Maryland School of Medicine, 110 S Paca Street, 8th Floor, Baltimore, MD 21201.E-mail: smola@peds.umaryland.edu.

DOI: $10.4187 /$ respcare. 03235

\section{QUICK LOOK}

\section{Current knowledge}

Advances in neonatal intensive care have resulted in an increase in the survival of very low birthweight (VLBW) infants. However, reductions in the incidence of bronchopulmonary dysplasia (BPD) have been small. Previous work has identified a reduction in the incidence of BPD in VLBW infants following the implementation of respiratory care quality improvement initiatives.

\section{What this paper contributes to our knowledge}

Implementation of a respiratory bundle in a single institution, which was primarily managed by respiratory therapists and nurses, increased the use of less invasive respiratory support in a consistent manner among VLBW infants. However, this intervention failed to show sustained reductions in the incidence of BPD.

practices after reviewing the respiratory care evidence available and comparing it to clinical practice: (1) early surfactant and extubation to CPAP to maintain functional residual capacity in preterm infants with respiratory distress syndrome and (2) oxygen saturation monitoring. Extensive education was provided to the nurses, respiratory therapists, neonatal nurse practitioners, physicians, and other ancillary staff regarding quality improvement, current evidence, and the implementation of each clinical change. An atmosphere of teamwork, consistency, and accountability was reinforced throughout the initiative.

\section{Potentially Better Practice Implementation}

A series of clinical practice changes were implemented as outlined in Figure 1. In early 2004, orders for lower target oxygen saturations of $88-92 \%$ and alarm limits of 85-95\% were implemented. ${ }^{7-19}$ Standardized $\mathrm{F}_{\mathrm{IO}_{2}}$ blending of nasal cannula was also implemented during that time period. Bedside nursing staff and respiratory therapists were instrumental in the standardization of these clinical changes. In 2005, a respiratory therapist-driven ventilator management protocol was developed and implemented in an effort to integrate additional clinical practice changes (Tables 1 and 2). The evidence-based clinical improvements in this bundle included prophylactic surfactant administration, standardized methylxanthine use, and functional residual capacity preservation through post-extubation CPAP. ${ }^{20,21}$ The evidence supporting surfactant prophylaxis in infants $<32 \mathrm{wk}$ gestation at that time was reviewed in the Neonatal Cochrane Review by Soll and Morley $^{20}$ in 2000, with the primary outcome variable of BPD or death. The relative risk benefit was 0.85 (95\% CI 


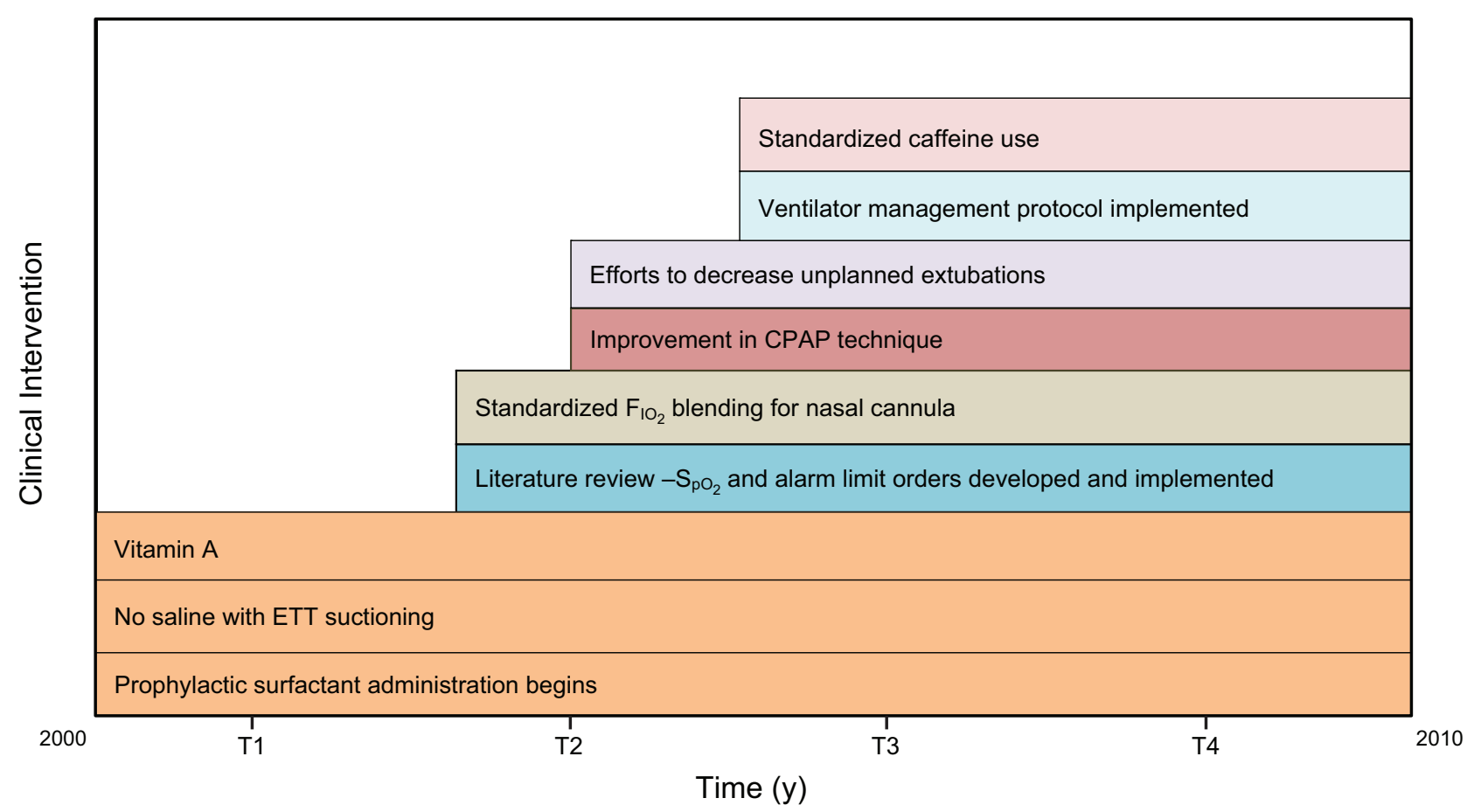

Fig. 1. Clinical intervention over time. T1 $=2002-2004, \mathrm{~T} 2=2004-2006, \mathrm{~T} 3=2006-2008, \mathrm{~T} 4=2008-2010 . \mathrm{ETT}=$ endotracheal tube.

Table 1. Standardized Ventilator Weaning Protocol

\begin{tabular}{|c|c|c|c|c|}
\hline Clinical Parameter & Wean & Tolerate & Evaluate & Weaning Intervention \\
\hline \multicolumn{5}{|l|}{ Ventilator } \\
\hline Expiratory $\mathrm{V}_{\mathrm{T}}(\mathrm{mL} / \mathrm{kg})$ & $5-6$ & $3-4$ & $<3$ or $>6$ & Decrease $\Delta \mathrm{P}$ (usually by decreasing PIP). \\
\hline Mechanical ventilation $(\mathrm{mL} / \mathrm{kg} / \mathrm{min})$ & $240-400$ & $160-240$ & $<160$ or $>400$ & $\begin{array}{l}\text { Decrease } \Delta \mathrm{P} \text { or breathing frequency, with goal } \\
\text { of reducing expiratory } \mathrm{V}_{\mathrm{T}} \text { first. }\end{array}$ \\
\hline \multicolumn{5}{|l|}{ Blood gas } \\
\hline $\mathrm{pH}$ & $7.28-7.35$ & $7.25-7.27$ & $<7.25$ or $>7.35$ & $\begin{array}{l}\text { If out-of-range } \mathrm{pH} \text { is respiratory in origin (vs metabolic), } \\
\text { adjust mechanical ventilation as above. If } \mathrm{P}_{\mathrm{aO}} \text { or } \mathrm{S}_{\mathrm{pO}_{2}} \\
\text { is less than desired, wean rate rather than PIP. }\end{array}$ \\
\hline $\mathrm{P}_{\mathrm{CO}_{2}}(\mathrm{~mm} \mathrm{Hg})$ & $41-56$ & $56-60$ & $<41$ or $>60$ & $\begin{array}{l}\text { Wean mechanical ventilation as above. If } \mathrm{P}_{\mathrm{aO}_{2}} \text { or } \mathrm{S}_{\mathrm{pO}_{2}} \\
\text { is less than desired, wean rate rather than PIP. }\end{array}$ \\
\hline $\mathrm{P}_{\mathrm{aO}_{2}}(\mathrm{~mm} \mathrm{Hg})(\mathrm{EGA} 23-31 \mathrm{wk})$ & $51-65$ & $41-50$ & $<41$ or $>65$ & $\begin{array}{l}\text { Adjust by manipulating mean airway pressure (primarily } \\
\text { by adjusting PEEP, but also with PIP or inspiratory time) } \\
\text { or } \mathrm{F}_{\mathrm{IO}_{2}} \text {. }\end{array}$ \\
\hline $\mathrm{P}_{\mathrm{aO}_{2}}(\mathrm{~mm} \mathrm{Hg})($ EGA 32-36 wk) & $56-70$ & $51-55$ & $<50$ or $>70$ & In general, do not wean PEEP until $\mathrm{F}_{\mathrm{IO}_{2}}<0.40$ \\
\hline $\begin{array}{l}\mathrm{V}_{\mathrm{T}}=\text { tidal volume } \\
\text { PIP = peak inspiratory pressure } \\
\text { EGA = estimated gestational age }\end{array}$ & & & & \\
\hline
\end{tabular}

$0.76-0.95)$, and the number needed to treat to result in 2 fewer deaths and 5 fewer pneumothoraces was 100 neonates. ${ }^{20}$ With this evidence, VON suggested a practice guideline to deliver surfactant prophylaxis to infants $<30$ wk gestation. Survanta (beractant) was used across the study period, with $4 \mathrm{~mL} / \mathrm{kg}$ administered in 2 aliquots with dosing every $6 \mathrm{~h}$ as needed via endotracheal tube for $\mathrm{F}_{\mathrm{IO}_{2}}$ requirements $\geq 0.30$ and/or a mean airway pressure $\geq 7 \mathrm{~cm} \mathrm{H}_{2} \mathrm{O}$, for a total of 4 doses.
Caffeine dosing and implementation was based upon the Schmidt et al ${ }^{21}$ study, which found extremely preterm infants randomized to receive caffeine in the first 7-10 d of life had a significantly reduced incidence of BPD. Infants $\leq 1,250 \mathrm{~g}$ or $\leq 30 \mathrm{wk}$ gestation who were intubated, who were being weaned from positive-pressure ventilation, and for whom extubation was planned received a loading dose of $20 \mathrm{mg} / \mathrm{kg}$ caffeine citrate (Cafcit) intravenously, followed by a daily maintenance dose of $5 \mathrm{mg} / \mathrm{kg}$. 
Table 2. Suggested Escalation

\begin{tabular}{|c|c|c|}
\hline Blood Gas Results & Possible Pathophysiology & Possible Responses With Ventilator \\
\hline $\mathrm{P}_{\mathrm{aCO}_{2}} \mathrm{OK} /$ low; $\mathrm{P}_{\mathrm{aO}_{2}}$ low & Atelectasis with $\dot{V} / \dot{Q}$ mismatch & Consider $\uparrow$ PEEP \\
\hline $\mathrm{P}_{\mathrm{aCO}_{2}} \mathrm{OK} /$ low; $\mathrm{P}_{\mathrm{aO}_{2}} \mathrm{OK} /$ high & Overventilated & Consider $\downarrow$ PIP, OR $\downarrow$ PIP and PEEP (with $\downarrow \Delta$ P), or $\downarrow$ rate \\
\hline $\mathrm{P}_{\mathrm{aCO}_{2}} \mathrm{OK} /$ high; $\mathrm{P}_{\mathrm{aO}_{2}}$ low & Atelectasis with resultant low $\mathrm{V}_{\mathrm{T}}$ & Consider $\uparrow \mathrm{PIP}$ OR $\uparrow$ PIP and PEEP (with $\uparrow \Delta \mathrm{P}$ ) \\
\hline $\mathrm{P}_{\mathrm{aCO}_{2}} \mathrm{OK} /$ high; $\mathrm{P}_{\mathrm{aO}_{2}}$ high & $\begin{array}{l}\text { Inadequate minute ventilation with } \\
\text { at least adequate FRC }\end{array}$ & Consider $\downarrow$ PEEP, $\uparrow$ rate, or $\uparrow$ PIP \\
\hline $\begin{array}{l}\mathrm{V} / \mathrm{Q}=\text { ventilation/perfusion } \\
\mathrm{PIP}=\text { peak inspiratory pressure } \\
\uparrow=\text { increase } \\
\downarrow=\text { decrease } \\
\mathrm{V}_{\mathrm{T}}=\text { tidal volume } \\
\mathrm{FRC}=\text { functional residual capacity }\end{array}$ & & \\
\hline
\end{tabular}

For continuing apnea, the daily dose could be increased to a maximum of $10 \mathrm{mg} / \mathrm{kg}$ caffeine citrate. This dosing was adjusted weekly for weight gain. Caffeine was continued until the infant was free of apnea requiring intervention for $7 \mathrm{~d}$. Drug levels were not routinely monitored except for symptoms of caffeine toxicity (tachycardia, tachypnea, tremors, seizures, jitteriness, or vomiting). Routine dosing time was established in the morning so that babies could share a vial due to cost of caffeine citrate.

\section{Existing Evidence-Based Improvements}

A number of potentially better practices identified as part of the TLC collaborative were already standard of care at this institution as a result of previous reviews of respiratory care literature. These included the use of vitamin A and suctioning without saline. ${ }^{22-32}$ Methylxanthines were also used by some clinicians, but not in a standardized fashion before implementation of the protocol. ${ }^{33-36}$

\section{Study Design}

After obtaining the hospital's institutional review board approval, we conducted a retrospective cohort study to investigate the incidence of BPD among VLBW infants before and after participation in a VON-sponsored NIC/Q focusing on noninvasive respiratory support. Four time periods (T1-T4) were identified: T1: September 1, 2002 to August 31, 2004; T2: September 1, 2004 to August 31, 2006; T3: September 1, 2006 to August 31, 2008; T4: September 1, 2008 to August 31, 2010. The majority of clinical interventions were implemented in $\mathrm{T} 2$ as noted in Figure 1. Baseline was defined as outcomes in T1. Outcomes in T3 were considered post-implementation outcomes, with outcomes in $\mathrm{T} 4$ representing sustainability of post-implementation outcomes.

De-identified data were obtained from a perinatal database that contains information on mother-baby pairs. Only inborn infants between $23 \mathrm{wk}$ and $29 \mathrm{wk}+6 \mathrm{~d}$ of gesta- tion were included in the study. Patients with congenital heart disease, significant congenital anomalies, or significant lung anomalies were excluded from the study. Patients were also excluded if death occurred without intubation, prophylactic surfactant, and mechanical ventilation, because the design of the study was to measure the effect of the respiratory bundle implementation.

\section{Clinical Definitions}

The clinical definitions were consistent with those published by VON. Infants requiring supplemental oxygen at 36 wk postmenstrual age (PMA) were classified as having BPD. To account for those infants discharged from the hospital before $36 \mathrm{wk}$ PMA, the definition of BPD was adjusted as follows: infants discharged from the hospital between $34 \mathrm{wk}$ and $35 \mathrm{wk}+6 \mathrm{~d}$ PMA on supplemental oxygen were classified as requiring oxygen at $36 \mathrm{wk}$ PMA and having BPD. Infants discharged to home without oxygen before 36 wk PMA or those in-patients not requiring supplemental oxygen at 36 wk PMA were categorized as not having BPD.

For the purposes of this study, prophylactic surfactant administration was defined as endotracheal administration by $1 \mathrm{~h}$ of life. Our clinical goal was endotracheal administration of surfactant by $15 \mathrm{~min}$ of life, followed by a period of brief mechanical ventilation. The infants were placed on pressure-limited ventilation in the delivery room for transport, and SIMV pressure-limited ventilation was continued upon admission to the NICU. Settings were weaned based upon the ventilator management protocol guidelines (Table 1). Subsequent surfactant dosing occurred at appropriate dosing intervals for mean airway pressures $\geq 7 \mathrm{~cm} \mathrm{H} \mathrm{H}_{2} \mathrm{O}$ or $\mathrm{F}_{\mathrm{IO}_{2}}$ requirement $\geq 0.30$. Surfactant dosing and ventilator management were respiratory therapistdriven, and weaning was performed based upon minute ventilation and tidal volume parameters as outlined in the protocol guidelines (Table 1). Infants were extubated to CPAP via nasal prongs. Suggestions for escalation were 


\section{NICU Bedside Caregivers Decrease BPD}

also provided with the protocol (Table 2). The protocol was developed based upon 2 prospective descriptive studies that present correlations between $\mathrm{P}_{\mathrm{aCO}}$ and minute ventilation in preterm neonates. ${ }^{37,38}$ At the time the workgroup convened, there were no studies addressing the use of ventilator weaning procotols for preterm neonates.

Lower oxygen saturation targeting of $88-92 \%$ was initially introduced in our NICU early in T2. This clinical change was further reinforced with the implementation of the ventilator management protocol that specified targeted oxygen saturations for titration of $\mathrm{F}_{\mathrm{IO}_{2}}$ by bedside nursing staff and respiratory therapists.

\section{Primary Outcomes}

Outcome measures were defined to be consistent with VON definitions as part of the TLC collaborative. Primary outcomes were defined as: rate of BPD (with adjusted definition as described under "Clinical Definitions") analyzed as BPD-free survival because death and BPD are competing outcomes. Clinically important outcomes, such as rates of survival and supplemental oxygen requirement at $28 \mathrm{~d}$, were also analyzed.

\section{Secondary Outcomes}

Secondary outcome measures were: rate of prophylactic surfactant and methylxanthine use, days of CPAP therapy, days on ventilator, rate of postnatal steroid use, rate of discharge from the hospital on supplemental oxygen, length of hospital stay, rate of pneumothorax, patent ductus arteriosus (PDA), culture-proven sepsis, necrotizing enterocolitis, severe intraventricular hemorrhage or periventricular leukomalacia, and severe retinopathy of prematurity.

\section{Statistical Analysis}

Data were tested for normal distribution. Non-normally distributed data were compared using Kruskal-Wallis test. Normally distributed data were compared by repeated measures analysis of variance. Other comparisons were made using chi-square, Fisher exact test, $\mathrm{R} \times \mathrm{C}$ contingency tables, and logistic regression models. Significance was defined a priori as $P<.05$.

\section{Results}

\section{Subject Demographics}

A total of 1,050 infants were included in the study. The number of inborn infants $<30 \mathrm{wk}$ gestation admitted to the NICU was similar in all time periods. There was a noted decrease in the number of inborn 23-24 wk infants admitted in T4; however, this was not a statistically sig- nificant trend when compared with the other defined time periods (Table 3). There was a significant difference in median birthweight and gestational age at delivery, with larger and more mature infants born in T4. This was expected, given the nonsignificant decrease in infants born at 23-24 wk PMA in T4. There were no differences in race, sex, or rate of small for gestational age infants between time periods.

As expected, there was a statistically significant increase in the rate of antenatal steroid therapy between time periods with $84 \%$ of mothers receiving therapy in $\mathrm{T} 1$ versus $92 \%$ in T4 $(P=.007)$. There was also a significant decrease in the rate of prenatal care between time periods (72\% in T1 vs $64 \%$ in T4, $P<.001)$. There was no difference in the rate of chorioamnionitis, multiple births, mode of delivery, or rate of intrauterine growth restriction in the analysis (Table 3).

\section{Primary Outcomes}

\section{Rate of BPD}

The rate of BPD as defined according to VON guidelines decreased significantly in T3 post-implementation of the respiratory bundle as compared with $\mathrm{T} 1$ (29.9\% vs $51.2 \%$, respectively; adjusted odds ratio $[\mathrm{aOR}]=0.06$ [95\% CI 0.03-0.13], $P=<.001$ ). In T4, there was a nonsignificant increase in the rate of BPD despite infants having a higher median gestational age and birthweight and fewer infants born at 23-24 wk gestation. There was not a significant difference between mortality rates in each time period $(13.3 \%$ in $\mathrm{T} 1$ vs $10.5 \%$ in T3, $P=0.31)$ and $(10.5 \%$ in $\mathrm{T} 3$ vs $6.7 \%$ in $\mathrm{T} 4, P=.12$ ) (Table 4 , Fig. 2).

\section{Rate of BPD-free Survival to Discharge}

After controlling for gender, gestational age, birthweight, rate of prenatal care, antenatal steroids, postnatal steroids, and presence of PDA, there was a significant increase in the rate of BPD-free survival to discharge in T3 compared with $\mathrm{T} 1$ (53\% vs 47\%; aOR $=1.68$ [95\% CI $1.11-2.56$ ], $P=.01)$. This demonstrates a marked improvement in the time period immediately following implementation of the respiratory care bundle. This improvement was not sustained, however, with the rate of BPD-free survival in T4 significantly decreasing to $41 \%$ compared with $53 \%$ in $\mathrm{T} 3$ $(\mathrm{aOR}=0.57$ [95\% CI 0.38-0.88], $P=.01)($ Table 4, Fig. 2).

\section{Rate of $\mathrm{O}_{2}$ at $28 \mathrm{~d}$}

The rate of infants requiring $\mathrm{O}_{2}$ at $28 \mathrm{~d}$ of life decreased significantly in $\mathrm{T} 3$ versus $\mathrm{T} 1$ ( $40.3 \%$ vs $69.9 \%$, respec- 
Table 3. Maternal and Infant Characteristics

\begin{tabular}{|c|c|c|c|c|c|}
\hline Maternal and Infant Characteristics & $\begin{array}{c}\mathrm{T} 1 \\
(n=270)\end{array}$ & $\begin{array}{c}\mathrm{T} 2 \\
(n=261)\end{array}$ & $\begin{array}{c}\mathrm{T} 3 \\
(n=266)\end{array}$ & $\begin{array}{c}\mathrm{T} 4 \\
(n=253)\end{array}$ & $P$ \\
\hline Prenatal care $(\%)$ & 71.8 & 82 & 69.6 & 64 & $<.001^{*}$ \\
\hline Antenatal steroids (\%) & 83.7 & 90.4 & 90.2 & 92.5 & $.007 *$ \\
\hline Chorioamnionitis (\%) & 7.4 & 9.6 & 12.8 & 9.9 & .22 \\
\hline Preeclampsia/eclampsia (\%) & 20.7 & 28 & 19.6 & 24.5 & .09 \\
\hline IUGR (\%) & 3.7 & 6.1 & 5.3 & 7.5 & .29 \\
\hline Multiple births (\%) & 24.8 & 21.5 & 23.3 & 27.3 & .47 \\
\hline Cesarean section $(\%)$ & 64.8 & 70.9 & 67.7 & 66.8 & .51 \\
\hline Gestational age (wk, median and IQR) & $27.4(26-28.6)$ & $27.1(25.4-28.5)$ & $27.4(25.6-28.5)$ & $27.5(26.2-29.1)$ & $.05^{*}$ \\
\hline Birth weight (g, median and IQR) & $995(745-1165)$ & $895(710-1125)$ & $922(740-1150)$ & $980(785-1210)$ & $.01 *$ \\
\hline Male $(\%)$ & 54.8 & 57.1 & 51.5 & 51.4 & .49 \\
\hline Black $(\%)$ & 49.6 & 57.9 & 59.4 & 57.7 & .09 \\
\hline SGA $(\%)$ & 12.6 & 10.7 & 9 & 9 & .49 \\
\hline 23-24 wk gestational age (\%) & 15.6 & 16.5 & 14.3 & 9.1 & .16 \\
\hline $25-26$ wk gestational age $(\%)$ & 22.2 & 29.9 & 25.6 & 24.9 & .16 \\
\hline 27 wk gestational age (\%) & 20 & 14.6 & 18.1 & 21.7 & .16 \\
\hline 28 wk gestational age (\%) & 17.8 & 16.1 & 19.2 & 15.4 & .16 \\
\hline 29 wk gestational age (\%) & 24.4 & 23 & 22.9 & 28.9 & .16 \\
\hline $\begin{array}{l}\mathrm{T} 1=\text { September } 1,2002 \text { to August } 31,2004 \\
\mathrm{~T} 2=\text { September } 1,2004 \text { to August } 31,2006 \\
\mathrm{~T} 3=\text { September } 1,2006 \text { to August } 31,2008 \\
\mathrm{~T} 4=\text { September } 1,2008 \text { to August } 31,2010 \\
\text { IUGR = rate of intrauterine growth restriction } \\
\text { IQR = interquartile range } \\
\text { SGA = small for gestational age } \\
* \text { Statistical significance }\end{array}$ & & & & & \\
\hline
\end{tabular}

Table 4. Primary Outcomes

\begin{tabular}{|c|c|c|c|c|c|c|}
\hline \multirow[b]{2}{*}{ Outcome } & \multirow{2}{*}{$\begin{array}{c}\text { T1 } \\
(n=270)\end{array}$} & \multirow{2}{*}{$\begin{array}{c}\mathrm{T} 2 \\
(n=261)\end{array}$} & \multirow{2}{*}{$\begin{array}{c}\text { T3 } \\
(n=266)\end{array}$} & \multirow{2}{*}{$\begin{array}{c}\mathrm{T} 4 \\
(n=253)\end{array}$} & \multicolumn{2}{|c|}{ OR $(95 \% \mathrm{CI})$} \\
\hline & & & & & $\begin{array}{c}\text { T3 compared } \\
\text { with } \mathrm{T} 1 \S\end{array}$ & $\begin{array}{c}\text { T4 compared } \\
\text { with } \mathrm{T} 3 \dagger\end{array}$ \\
\hline BPD-free survival to discharge $(\%)$ & 47 & 45.2 & 53.1 & 41.1 & $1.68(1.11-2.56)^{*}$ & $0.57(0.38-0.88)^{*}$ \\
\hline $\mathrm{O}_{2}$ at 36 wk PMA or home on $\mathrm{O}_{2}(\%)$ & 51.2 & 48 & 29.9 & 42.3 & $0.06(0.03-0.13)^{*}$ & $1.55(0.73-3.28)$ \\
\hline $\mathrm{O}_{2}$ at $28 \mathrm{~d}(\%)$ & 69.9 & 57.9 & 40.3 & 41.5 & $0.12(0.07-0.20)^{*}$ & $1.03(0.60-1.76)$ \\
\hline \multicolumn{7}{|l|}{$\overline{\mathrm{T} 1}=$ September 1,2002 to August 31, 2004} \\
\hline \multicolumn{7}{|l|}{$\mathrm{T} 2=$ September 1, 2004 to August 31, 2006} \\
\hline \multicolumn{7}{|l|}{$\mathrm{T} 3=$ September 1, 2006 to August 31,2008} \\
\hline \multicolumn{7}{|l|}{$\mathrm{T} 4=$ September 1,2008 to August 31,2010} \\
\hline \multicolumn{7}{|l|}{$\mathrm{OR}=$ odds ratio } \\
\hline \multicolumn{7}{|l|}{$\mathrm{BPD}=$ bronchopulmonary dysplasia } \\
\hline \multicolumn{7}{|l|}{ PMA $=$ postmenstrual age } \\
\hline \multicolumn{7}{|l|}{ * Statistical significance } \\
\hline \multirow{2}{*}{\multicolumn{7}{|c|}{$\begin{array}{l}\dagger \text { Odds ratios with } 95 \% \text { confidence intervals were calculated for } \mathrm{T} 4 \text { when compared to } \mathrm{T} 3 \text { controlling for gender, gestational age, birth weight, rate of prenatal care, antenatal steroids, postnatal } \\
\text { steroids, and presence of PDA }\end{array}$}} \\
\hline \multicolumn{3}{|l|}{$\ddagger$ Vermont Oxford Network definition of BPD } & & & & \\
\hline $\begin{array}{l}\text { \& Odds ratios with } 95 \% \text { confidence intervals were cal } \\
\text { steroids, and presence of PDA }\end{array}$ & f for $\mathrm{T} 3$ when & ired to $\mathrm{T} 1$ contr & for gender, ge & age, birth n & ate of prenatal care, an & steroids, postnatal \\
\hline
\end{tabular}

tively; $\mathrm{aOR}=0.12$ [95\% CI 0.07-0.20], $P=<.001$ ). There was no significant change in rate of $\mathrm{O}_{2}$ requirement at $28 \mathrm{~d}$ between $\mathrm{T} 3$ and T4, implying a sustained decrease in the rate of VLBW infants requiring $\mathrm{O}_{2}$ at $28 \mathrm{~d}$ postimplementation of the respiratory bundle when compared with rates pre-implementation in T1 (Table 4, Fig. 2).

\section{Secondary Outcomes}

As expected, there was a significant trend toward improvement in the rate of prophylactic surfactant administration and methylxanthine use over the 8-y study period. In $\mathrm{T} 1,78.9 \%$ of infants received prophylactic surfactant 


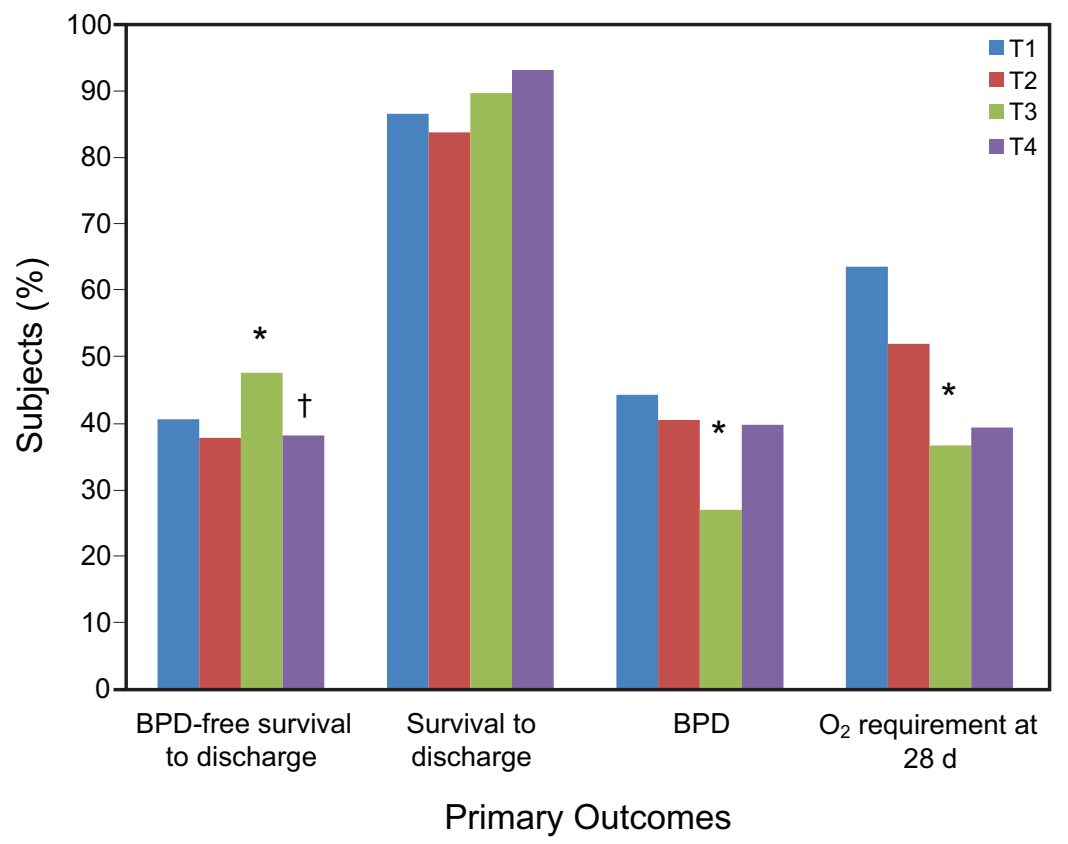

Fig. 2. A significant decrease in the rate of BPD was noted in T3 compared with $\mathrm{T} 1$ (29.9\% vs $51.2 \%$, respectively; adjusted odds ratio $[\mathrm{aOR}]=0.06[95 \% \mathrm{Cl} 0.03-0.13] ; P<.001)$ as well as a decrease in $\mathrm{O}_{2}$ requirement at $28 \mathrm{~d}(40.3 \%$ vs $69.9 \%$, respectively; aOR $=0.119$ $[95 \% \mathrm{Cl} 0.07-0.20] ; P<.001)$. Similarly, there was significant increase in the rate of BPD-free survival to discharge between T1 and T3 (53.1\% vs 47\%; aOR $=1.68$ [95\% Cl 1.11-2.56]; $P<.01$ ) that significantly decreased from T3 to T4. There was no significant difference in mortality rates for each time period. T1 $=2002-2004, \mathrm{~T} 2=2004-2006, \mathrm{~T} 3=2006-2008, \mathrm{~T} 4=2008-2010$. ${ }^{*}$ denotes significant change between $\mathrm{T} 1$ and $\mathrm{T} 3$. $\dagger$ denotes significant change between T3 and T4.

by $1 \mathrm{~h}$ of life versus $95.3 \%$ in $\mathrm{T} 4(P<.001)$. The rate of caffeine use increased from $47.4 \%$ in $\mathrm{T} 1$ to $98 \%$ in $\mathrm{T} 4$ $(P<.001)$. Median ventilator days were significantly decreased by $>50 \%$ from $\mathrm{T} 1$ to $\mathrm{T} 4$, with an expected subsequent increase in post-extubation CPAP days (Table 5). There was not a statistically significant difference between length of hospital stay or rates of pneumothorax, cultureproven sepsis, severe intraventricular hemorrhage or periventricular leukomalacia, and severe retinopathy of prematurity between time periods. There was an unexpected yet significant increase in the rate of PDA and postnatal steroid use in T4 when compared with T1 (21.9\% vs $39.1 \%$, $P<.001$ and $12.6 \%$ vs $24.1 \% P<.001$, respectively) (Table 5).

\section{Discussion}

In this study, implementation of a respiratory bundle managed primarily by nurses and respiratory therapists was successful in implementing less invasive respiratory support and decreasing oxygen exposure in a consistent manner among VLBW infants at a single institution. However, this study failed to show sustained improvement in the incidence of BPD despite sustained process change. Significant clinical improvements have been sustained through 4 y post-implementation such as the significant decrease in ventilator days and increase in CPAP days. Additionally, an increase in the percentage of infants receiving surfactant in the first postnatal hour and infants receiving caffeine therapy demonstrates continued utilization of these specific clinical interventions in the bundle.

A decreased BPD rate was appreciated in the first 2 y after implementation at our institution. Following logistic regression analysis controlling for the significant confounders including gender, gestational age, birthweight, rate of prenatal care, antenatal steroids, postnatal steroids, and presence of PDA, this significant decrease persisted. However, a nonsignificant, yet marked increase in the rate of BPD was noted in T4 when compared with T3. Additionally, when comparing survival without BPD at discharge by time period, a statistically significant increase was noted 2 y post-implementation that was not sustained. This raises concern that, despite a persistent decrease in ventilator days, an increase in CPAP, an increase in prophylactic surfactant delivery, and an increase in caffeine therapy, these evidence-based clinical improvements are not associated with improvement in long-term respiratory outcomes.

A unique characteristic of our intervention was reliance predominantly upon the bedside caregivers for implementation and maintenance. Only one other pediatric study has evaluated bedside caregiver-dependent quality improve- 
Table 5. Secondary Outcomes

\begin{tabular}{|c|c|c|c|c|c|}
\hline Outcome & $\mathrm{T} 1(n=270)$ & $\mathrm{T} 2(n=261)$ & $\mathrm{T} 3(n=266)$ & $\mathrm{T} 4(n=253)$ & $P$ \\
\hline Surfactant by $1 \mathrm{~h}$ of life (\%) & 78.9 & 90 & 93.2 & 95.3 & $<.001^{*}$ \\
\hline Caffeine therapy (\%) & 47.4 & 53.6 & 89.9 & 98 & $<.001^{*}$ \\
\hline Ventilator ( $\mathrm{d}$, median and IQR) & $8.5(2.0-32.0)$ & $8.0(2.0-33.0)$ & $3.5(1.0-23.0)$ & $4.0(1.0-23.0)$ & $<.001^{*}$ \\
\hline CPAP (d, median and IQR) & $4.0(2.0-6.0)$ & $4.0(2.0-11.0)$ & $8.0(3.0-16.5)$ & $8.0(4.0-19.0)$ & $<.001^{*}$ \\
\hline Postnatal steroids (\%) & 12.6 & 18.8 & 18.8 & 24.1 & $.009 *$ \\
\hline Length of stay (d, median and IQR) & $54.5(36.0-78.0)$ & $53.0(35.0-80.0)$ & $52.0(36.0-71.0)$ & $55.0(41.0-76)$ & .4 \\
\hline Home on $\mathrm{O}_{2}(\%)$ & 44.4 & 50.2 & 44.8 & 54.2 & .1 \\
\hline Pneumothorax $(\%)$ & 3 & 5 & 6 & 4 & .36 \\
\hline PDA $(\%)$ & 21.9 & 31.4 & 24.8 & 39.1 & $<.001^{*}$ \\
\hline Early sepsis, culture proven (\%) & 1.1 & 1.9 & 1.9 & 0.8 & .62 \\
\hline Severe IVH or PVL (\%) & 19.3 & 17.2 & 19.2 & 15.4 & .62 \\
\hline Severe ROP $(\%)$ & 6.7 & 5.4 & 4.5 & 5.1 & .73 \\
\hline $\begin{array}{l}\mathrm{T} 1=\text { September } 1,2002 \text { to August } 31,2004 \\
\mathrm{~T} 2=\text { September } 1,2004 \text { to August } 31,2006 \\
\mathrm{~T} 3=\text { September } 1,2006 \text { to August } 31,2008 \\
\mathrm{~T} 4=\text { September } 1,2008 \text { to August } 31,2010 \\
\mathrm{IQR}=\text { interquartile range } \\
\mathrm{PDA}=\text { patent ductus arteriosus } \\
\mathrm{IVH}=\text { intraventricular hemorrhage } \\
\mathrm{PVL}=\text { periventricular leukomalacia } \\
\text { ROP = retinopathy of prematurity } \\
* \text { Statistical significance }\end{array}$ & & & & & \\
\hline
\end{tabular}

ments in respiratory care. Hermeto et al ${ }^{39}$ reported the implementation of a respiratory therapist-driven ventilator protocol that was associated with shortened time to first extubation attempt, increased rate of successful extubation, and decreased duration under mechanical ventilation in infants $<1,250 \mathrm{~g}$ at birth. There was also a nonsignificant, yet appreciable decrease in rate of infants requiring oxygen at $28 \mathrm{~d}$. The incidence of BPD, or oxygen requirement at 36 wk PMA, was not statistically different between groups. The study was not powered sufficiently to examine these respiratory outcomes. There are few pediatric articles describing pediatric ventilator protocols and outcomes..$^{40,41}$ This is in contrast to the adult literature, in which several randomized trials and prospective case series involving protocols directed by nursing, respiratory therapy, and computers have been associated with decreased times on mechanical ventilation and other improved outcomes. ${ }^{42-47}$

A 2004 study by Aly et al ${ }^{48}$ demonstrated sustainable improvements in the rates of BPD and similar outcome variables such as a decrease in ventilator days and an increase in CPAP use after implementation of an early nasal CPAP management strategy. Other studies have evaluated respiratory care interventions but without a measurement of sustainability. Birenbaum and colleagues ${ }^{5}$ demonstrated successful process outcomes such as increased use of the T-piece resuscitator in the delivery room, increased use of nasal CPAP in the delivery room, and decreased time on mechanical ventilation at a single institution. They found a reduction in the incidence of BPD from
$46.5 \%$ in 2002 to $20.5 \%$ in 2005 , with an overall relative risk reduction of $55.8 \%$ following implementation of quality improvements. However, they did not evaluate the ability to sustain these clinical processes or results.

Likewise, the NIC/Q Breathsavers group in 2002 noted improvements in process outcomes including decreased time on mechanical ventilation, time to initial surfactant administration, and increased CPAP use following identification and implementation of 13 potentially better practices among 18 participating centers. There was also a noted $27 \%$ overall reduction in the incidence of BPD over a 2-y period following implementation of clinical modifications. ${ }^{4,49}$ However, the participating centers aimed at reducing BPD rates demonstrated markedly varying results. Some NICUs with low baseline rates of BPD demonstrated paradoxical increases in BPD rates. ${ }^{6}$ Payne et $\mathrm{al}^{4}$ described the possibility of the Hawthorne effect, or the improvement in performance that is seen when performance receives extra scrutiny, that may have contributed to improved outcomes in their study. Participants in these collaboratives are also self-selected and highly motivated individuals, and these factors may well have contributed to the improved rates of BPD initially observed with the Breathsavers group, as well as with our study. ${ }^{6}$ It is a possibility that our bedside caregivers experienced "bundle fatigue" with time, which may have contributed to the increase in BPD rates observed in T4 in our study.

Another monitor of respiratory outcomes is survival without BPD, or BPD-free survival. In a cluster-randomized trial that involved 17 centers of the National Institute of 


\section{NICU Bedside Caregivers Decrease BPD}

Child Health and Human Development (NICHD) Neonatal Research Network, benchmarking and multimodal quality improvement were successful in changing practice such as reducing oxygen exposure and mechanical ventilation duration, but did not reduce the rate of survival free of BPD. ${ }^{50}$ Similarly, Horbar et al ${ }^{51}$ did not demonstrate a significant decrease in the combined outcome of death or $\mathrm{O}_{2}$ supplementation at $36 \mathrm{wk}$ despite significant measureable process change in the 4 participating NICUs. These findings are consistent with the results of our observational study that, despite successful, sustained implementation of evidence-based quality improvements in respiratory care emphasizing noninvasive respiratory support, long-term outcomes such as BPD-free survival may not sustain positive change.

What could account for the discrepancy of improved respiratory care with less oxygen need at $28 \mathrm{~d}$ but with persistence in prevalence of BPD? BPD is known to be a complex, multifactorial disease process, illustrated by the finding that some VLBW infants demonstrate little to no initial lung disease, but subsequently develop BPD. ${ }^{52}$ Barotrauma and volutrauma by mechanical ventilation, combined with atelectotrauma, and exposure to oxygen toxicity contribute to inflammatory reactions that persist past the immediate neonatal period and contribute to the development of BPD. ${ }^{53-56}$

At the time of this study, there was only one T-piece resuscitator available in the NICU for bedside resuscitation or unintended extubation. This was often reserved for the most immature or critically-ill infants, or infants with air leak. Otherwise, a neonatal manual resuscitation bag would have been utilized in those clinical situations. There were also no $\mathrm{F}_{\mathrm{IO}_{2}}$ blenders at bedside at the time of the study. T-piece resuscitators and blended $\mathrm{F}_{\mathrm{IO}_{2}}$ were present and utilized for all VLBW deliveries in the delivery room. One could speculate that respiratory care administered at the bedside with bag-valve-mask and oxygen exposure may be a significant contributor to the development of BPD. As animal studies have demonstrated, just 6 large tidal volume breaths had potential to cause severe preterm lamb lung injury. ${ }^{57}$ The subsequent inflammatory response that ensues may contribute to a protracted course of lung injury. Unfortunately there was no standardized collection of data surrounding unintended extubations or number of positive-pressure events at bedside in the NICU at the time of the study. The lack of this pertinent clinical information is a limitation to our study, given the retrospective study design.

There has also been emerging evidence to suggest that initiation of CPAP for extremely preterm infants is an acceptable alternative to prophylactic surfactant administration. The SUPPORT Study Group of the Eunice Kennedy Shriver NICHD Neonatal Research Network randomized $>1,300$ extremely low birthweight neonates to either CPAP or intubation, prophylactic surfactant within $1 \mathrm{~h}$ of life followed by a brief period of ventilation. The primary outcome of death or BPD was no different between the groups. However, infants who received CPAP treatment, as compared with infants who received surfactant treatment, less frequently required intubation or postnatal corticosteroids for BPD $(P<.001)$, required fewer days of mechanical ventilation $(P=.03)$, and were more likely to be alive and free from the need for mechanical ventilation by day $7(P=.01)$. The rates of other adverse neonatal outcomes did not differ significantly between the 2 groups. ${ }^{58}$ The design of our bundle incorporates a brief period of mechanical ventilation and a weaning protocol similar to the prophylactic surfactant arm of this study. Any positive-pressure ventilation delivered to preterm infants may contribute to a cascade of inflammatory reactions that may subsequently contribute to the development of BPD. ${ }^{57}$ Given the SUPPORT trial outcome, early use of noninvasive support such as CPAP without intubation and ventilation may have also contributed to the sustained success documented by Aly et $\mathrm{al}^{48}$ in decreasing the incidence of BPD at their institution.

Another reason for the discrepancy between improved respiratory techniques and sustained outcome may be that definitions of BPD lack a rigorous, consistent approach to integrating oxygen delivery into the diagnosis. Walsh and colleagues ${ }^{59}$ demonstrated that the development and implementation of a rigorous physiologic definition of BPD that included a room air challenge for infants receiving $<30 \%$ effective oxygen resulted in a mean reduction of $10 \%$ in rates of BPD. At the time this study was conducted, no uniform guidelines for nasal cannula weaning or for a room air challenge at 36 wk PMA were in place at our institution. Additionally, some clinicians implement oxygen therapy for preterm infants with poor oral feeding technique or apnea and desaturation events during feeds. Infants may be discharged to home on oxygen solely to be utilized during feeds and are misdiagnosed as having BPD without meeting true physiologic criteria. Despite little evidence to support this practice, it continues to occur and may contribute to the discrepancy noted between $\mathrm{O}_{2}$ requirement at $28 \mathrm{~d}$ and $36 \mathrm{wk}$ PMA at this institution.

An unexpected outcome in our study was a nonsignificant, yet marked increase in the use of postnatal steroids during the study period. However, despite the rise in postnatal steroid use, the rate of BPD continued to increase from T3 to T4 after controlling for this variable. Since the American Academy of Pediatrics policy statement in 2002 stating that routine dexamethasone therapy could not be recommended without further study and long-term followup, postnatal steroid use in preterm infants has decreased. ${ }^{60}$ There have been 2 randomized controlled trials published since the 2002 policy statement demonstrating increased successful extubation with later, low-dose dexamethasone 


\section{NICU Bedside Caregivers Decrease BPD}

compared with control. Neither study was powered to evaluate the effect of the treatment on survival without BPD. ${ }^{61,62}$ The increase in steroid use at our institution noted during this study may be in part to the adoption of practice to administer later, low-dose dexamethasone to facilitate extubation in chronically ventilated infants. This has been noted as a potential confounder as well as limitation in this retrospective study design.

The increased rate of PDA observed across the study period was also an unexpected outcome. The increase in rate of PDA may be explained by a few clinical factors. There was practice variation among clinicians regarding PDA management. Data regarding management strategies were not collected, and this is a limitation to the study. The practice to give prophylactic indomethacin to neonates $<1,000 \mathrm{~g}$ at birth was routine among clinicians early in the study period. However, this practice was discontinued in T4. This time point was not collected and not accounted for in the statistical analysis. There was also practice variation among obstetricians regarding agents used for tocolysis of preterm labor. Indomethacin was frequently used as a tocolytic agent during this time period and could also contribute to the increased rates of PDA if fewer women received prenatal care, and therefore indomethacin exposure. The data regarding use of indomethacin for tocolysis among the obstetricians were not collected and accounted for in the statistical analysis and are therefore another limitation to the study.

There are few data supporting the role of PDA in the development of BPD. To date, there is only one randomized controlled trial, which was performed in the 1970s, that has examined the pulmonary effects of prolonged exposure to PDA in extremely premature infants requiring mechanical ventilation. The investigators compared the effects of ligating the PDA versus allowing PDA to persist and found that ligation decreased the need for prolonged mechanical ventilation. ${ }^{63}$ Studies have suggested that the mean airway pressure and $\mathrm{F}_{\mathrm{IO}_{2}}$ needed to overcome PDAinduced changes in pulmonary compliance may contribute to the development of BPD; however, there is little evidence from controlled clinical trials. ${ }^{63-65}$ An additional limitation of the study is the lack of data such as mean airway pressures, mean CPAP levels, and $\mathrm{F}_{\mathrm{IO}_{2}}$ requirements. In addition, because it was a before-and-after study, the possibility exists that other unrecognized changes were taking place concurrently with the study.

\section{Conclusions}

In this study, implementation of a respiratory bundle managed primarily by nurses and respiratory therapists was successful in increasing the use of less invasive respiratory support in a consistent manner among VLBW infants at a single institution. In doing so, the rate of BPD was improved in the $2 \mathrm{y}$ after implementation of the protocol. This demonstrates that improvement in complex outcomes such as BPD may be achieved through quality improvement methodology involving primarily bedside caregivers. However, this study and several others have failed to show sustainability in improvement of this complex respiratory outcome despite sustained process change. This warrants further study into the pathogenesis of BPD and the optimal team factors to determine the best practices for decreasing BPD rates in a sustainable fashion.

\section{REFERENCES}

1. Jobe AH. Mechanisms to explain surfactant responses. Biol Neonate 2006;89(4):298-302.

2. Varughese M, Patole S, Shama A, Whitehall J. Permissive hypercapnia in neonates: the case of the good, the bad, and the ugly. Pediatr Pulmonol 2002;33(1):56-64.

3. Clark RH, Gerstmann DR, Jobe AH, Moffitt ST, Slutsky AS, Yoder BA. Lung injury in neonates: causes, strategies for prevention, and long-term consequences. 2001;139(4):478-486.

4. Payne NR, LaCorte M, Karna P, Chen S, Finkelstein M, Goldsmith JP, et al. Reduction of bronchopulmonary dysplasia after participation in the Breathsavers Group of the Vermont Oxford Network Neonatal Intensive Care Quality Improvement Collaborative. Pediatrics 2006;118 (Suppl 2):S73-S77.

5. Birenbaum HJ, Dentry A, Cirelli J, Helou S, Pane MA, Starr K, et al. Reduction in the incidence of chronic lung disease in very low birth weight infants: results of a quality improvement process in a tertiary level neonatal intensive care unit. Pediatrics 2009;123(1):44-50.

6. Pfister RH, Goldsmith JP. Quality improvement in respiratory care: decreasing bronchopulmonary dysplasia. Clin Perinatol 2010;37(1): 273-293.

7. Tin W, Milligan DW, Pennefather P, Hey E. Pulse oximetry, severe retinopathy, and outcome at one year in babies of less than 28 weeks gestation. Arch Dis Child Fetal Neonatal Ed 2001;84(2):F106-F110.

8. Chow LC, Wright KW, Sola A, CSMC Oxygen Administration Study Group. Can changes in clinical practice decrease the incidence of severe retinopathy of prematurity in very low birth weight infants? Pediatrics 2003;111(2):339-345.

9. Anderson CG, Benitz WE, Madan A. Retinopathy of prematurity and pulse oximetry: a national survey of recent practices. J Perinatol 2004;24(3):164-168.

10. Rabi Y, Rabi D, Yee W. Room air resuscitation of the depressed newborn: a systematic review and meta-analysis. Resuscitation 2007; 72(3):353-363

11. Silvers KM, Gibson AT, Russell JM, Powers HJ. Antioxidant activity, packed cell transfusions, and outcome in premature infants. Arch Dis Child Fetal Neonatal Ed 1998;78(3):F214-F219.

12. Saugstad OD. Bronchopulmonary dysplasia and oxidative stress: are we closer to an understanding of the pathogenesis of BPD? Acta Paediatr 1997;86(12):1277-1282.

13. Davis JM. Role of oxidant injury in the pathogenesis of neonatal lung disease. Acta Paediatr Suppl 2002;91(437):23-25.

14. Jobe AH, Bancalari E. Bronchopulmonary dysplasia. Am J Respir Crit Care Med 2001;163(7):1723-1729.

15. Wright KW, Sami D, Thompson L, Ramanathan R, Joseph R, Farzavandi S. A physiologic reduced oxygen protocol decreases the incidence of threshold retinopathy of prematurity. Trans Am Ophthalmol Soc 2006;104:78-84.

16. Askie LM, Henderson-Smart DJ, Irwig L, Simpson JM. Oxygensaturation targets and outcomes in extremely preterm infants. N Engl J Med 2003;349(10):959-967. 


\section{NICU Bedside Caregivers Decrease BPD}

17. Supplemental Therapeutic Oxygen for Prethreshold Retinopathy Of Prematurity (STOP-ROP), a randomized, controlled trial. I: Primary outcomes. Pediatrics 2000;105(2):295-310.

18. Gaynon MW, Stevenson DK. What can we learn from STOP-ROP and earlier studies? Pediatrics 2000;105(2):420-421.

19. Hay WW Jr, Bell EF. Oxygen therapy, oxygen toxicity, and the STOP-ROP trial. Pediatrics 2000;105(2):424-425.

20. Soll RF, Morley CJ. Prophylactic versus selective use of surfactant for preventing morbidity and mortality in preterm infants. Cochrane Database Syst Rev 2000;(2):CD000510.

21. Schmidt B, Roberts RS, Davis P, Doyle LW, Barrington KJ, Ohlsson A, et al. Caffeine therapy for apnea of prematurity. N Engl J Med 2006;354(20):2112-2121.

22. Hagler DA, Traver GA. Endotracheal saline and suction catheters: sources of lower airway contamination. Am J Crit Care 1994;3(6): 444-447.

23. Ridling DA, Martin LD, Bratton SL. Endotracheal suctioning with or without instillation of isotonic sodium chloride solution in critically ill children. Am J Crit Care 2003;12(3):212-219.

24. Beeram MR, Dhanireddy R. Effects of saline instillation during tracheal suction on lung mechanics in newborn infants. J Perinatol 1992;12(2):120-123.

25. Kinloch D. Instillation of normal saline during endotracheal suctioning: effects on mixed venous oxygen saturation. 1999; Am J Crit Care 8(4):231-240; quiz 241-232.

26. Shorten DR, Byrne PJ, Jones RL. Infant responses to saline instillations and endotracheal suctioning. J Obstet Gynecol Neonatal Nursing 1991;20(6):464-469.

27. Bostick J, Wendelgass ST. Normal saline instillation as part of the suctioning procedure: effects on $\mathrm{PaO} 2$ and amount of secretions. Heart Lung J Crit Care 1987;16(5):532-537.

28. Shenai JP, Chytil F, Jhaveri A, Stahlman MT. Plasma vitamin A and retinol-binding protein in premature and term neonates. J Pediatr 1981;99(2):302-305.

29. Darlow BA, Graham PJ. Vitamin A supplementation to prevent mortality and short and long-term morbidity in very low birthweight infants. Cochrane Database Syst Rev 2007;(4):CD000501.

30. Ambalavanan N, Wu TJ, Tyson JE, Kennedy KA, Roane C, Carlo WA. A comparison of three vitamin A dosing regimens in extremely-low-birth-weight infants. J Pediatr 2003;142(6):656-661.

31. Tyson JE, Wright LL, Oh W, Kennedy KA, Mele L, Ehrenkranz RA, et al. Vitamin A supplementation for extremely-low-birth-weight infants. National Institute of Child Health and Human Development Neonatal Research Network. N Engl J Med 1999;340(25):1962-1968.

32. Carlo WA, Stark AR, Wright LL, Tyson JE, Papile LA, Shankaran $\mathrm{S}$, et al. Minimal ventilation to prevent bronchopulmonary dysplasia in extremely-low-birth-weight infants. J Pediatr 2002;141(3):370374.

33. Henderson-Smart DJ, Steer P. Methylxanthine treatment for apnea in preterm infants. Cochrane Database Syst Rev 2001;(3):CD000140.

34. Henderson-Smart DJ, Davis PG. Prophylactic methylxanthines for extubation in preterm infants. Cochrane Database Syst Rev 2003; (1):CD000139.

35. Steer PA, Flenady VJ, Shearman A, Lee TC, Tudehope DI, Charles BG. Periextubation caffeine in preterm neonates: a randomized dose response trial. J Paediatr Child Health 2003;39(7):511-515.

36. Steer P, Flenady V, Shearman A, Charles B, Gray PH, HendersonSmart D, et al. High dose caffeine citrate for extubation of preterm infants: a randomised controlled trial. Arch Dis Child Fetal Neonatal Ed 2004;89(6):F499-503.

37. Mathur NB, Bhatia V. Effect of stepwise reduction in minute ventilation on $\mathrm{PaCO} 2$ in ventilated newborns. Indian Pediatr 2004;41(8): 779-785.
38. Davies MW, Kecskes ZB, Berrington J. Determining the ventilatory volumes required to ventilate low birth weight infants with respiratory distress syndrome: prediction of arterial carbon dioxide using minute volumes. Biol Neonate 2002;82(4):233-237.

39. Hermeto F, Bottino MN, Vaillancourt K, Sant'Anna GM. Implementation of a respiratory therapist-driven protocol for neonatal ventilation: impact on the premature population. Pediatrics 2009;123(5): e907-e916.

40. Randolph AG, Wypij D, Venkataraman ST, Hanson JH, Gedeit RG, Meert KL, et al. Effect of mechanical ventilator weaning protocols on respiratory outcomes in infants and children: a randomized controlled trial. J Am Med Assoc 2002;288(20):2561-2568.

41. Schultz TR, Lin RJ, Watzman HM, Durning SM, Hales R, Woodson A, et al. Weaning children from mechanical ventilation: a prospective randomized trial of protocol-directed versus physician-directed weaning. Respir Care 2001;46(8):772-782.

42. Ely EW, Meade MO, Haponik EF, Kollef MH, Cook DJ, Guyatt GH, et al. Mechanical ventilator weaning protocols driven by nonphysician health-care professionals: evidence-based clinical practice guidelines. Chest 2001;120(6 Suppl):454S-463S.

43. Ely EW, Baker AM, Dunagan DP, Burke HL, Smith AC, Kelly PT, et al. Effect on the duration of mechanical ventilation of identifying patients capable of breathing spontaneously. N Engl J Med 1996; 335(25):1864-1869.

44. Kollef MH, Shapiro SD, Silver P, St John RE, Prentice D, Sauer S, et al. A randomized, controlled trial of protocol-directed versus physician-directed weaning from mechanical ventilation. Crit Care Med 1997;25(4):567-574.

45. Marelich GP, Murin S, Battistella F, Inciardi J, Vierra T, Roby M. Protocol weaning of mechanical ventilation in medical and surgical patients by respiratory care practitioners and nurses: effect on weaning time and incidence of ventilator-associated pneumonia. Chest 2000;118(2):459-467.

46. Girard TD, Kress JP, Fuchs BD, Thomason JW, Schweickert WD, Pun BT, et al. Efficacy and safety of a paired sedation and ventilator weaning protocol for mechanically ventilated patients in intensive care (Awakening and Breathing Controlled trial): a randomised controlled trial. Lancet 2008;371(9607):126-134.

47. Girard TD, Ely EW. Protocol-driven ventilator weaning: reviewing the evidence. Clin Chest Med 2008;29(2):241-252, v.

48. Aly H, Milner JD, Patel K, El-Mohandes AA. Does the experience with the use of nasal continuous positive airway pressure improve over time in extremely low birth weight infants? Pediatrics 2004; 114(3):697-702.

49. Payne NR, LaCorte M, Sun S, Karna P, Lewis-Hunstiger M, Goldsmith JP, et al. Evaluation and development of potentially better practices to reduce bronchopulmonary dysplasia in very low birth weight infants. Pediatrics 2006;118 Suppl 2:S65-S72.

50. Walsh M, Laptook A, Kazzi SN, Engle WA, Yao Q, Rasmussen M, et al. A cluster-randomized trial of benchmarking and multimodal quality improvement to improve rates of survival free of bronchopulmonary dysplasia for infants with birth weights of less than 1250 grams. Pediatrics 2007;119(5):876-890.

51. Horbar JD, Rogowski J, Plsek PE, Delmore P, Edwards WH, Hocker $\mathrm{J}$, et al. Collaborative quality improvement for neonatal intensive care. NIC/Q Project Investigators of the Vermont Oxford Network. Pediatrics 2001;107(1):14-22.

52. Bancalari E. Bronchopulmonary dysplasia: old problem, new presentation. J Pediatr (Rio J) 2006;82(1):2-3.

53. Pierce MR, Bancalari E. The role of inflammation in the pathogenesis of bronchopulmonary dysplasia. Pediatr Pulmonol 1995;19(6): 371-378. 


\section{NICU Bedside Caregivers Decrease BPD}

54. Groneck P, Speer CP. Inflammatory mediators and bronchopulmonary dysplasia. Arch Dis Child Fetal Neonatal Ed 1995;73(1): F1-3.

55. Ozdemir A, Brown MA, Morgan WJ. Markers and mediators of inflammation in neonatal lung disease. Pediatr Pulmonol 1997;23(4): 292-306.

56. Munshi UK, Niu JO, Siddiq MM, Parton LA. Elevation of interleukin- 8 and interleukin- 6 precedes the influx of neutrophils in tracheal aspirates from preterm infants who develop bronchopulmonary dysplasia. Pediatr Pulmonol 1997;24(5):331-336.

57. Bjorklund LJ, Ingimarsson $\mathrm{J}$, Curstedt $\mathrm{T}$, John $\mathrm{J}$, Robertson $\mathrm{B}$, Werner $\mathrm{O}$, et al. Manual ventilation with a few large breaths at birth compromises the therapeutic effect of subsequent surfactant replacement in immature lambs. Pediatr Res 1997;42(3):348-355.

58. SUPPORT Study Group of the Eunice Kennedy Shriver NICHD Neonatal Research Network, Finer NN, Carlo WA, Walsh MC, Rich W, Gantz MG, et al. Early CPAP versus surfactant in extremely preterm infants. N Engl J Med 2010;362(21):1970-1979.

59. Walsh MC, Yao Q, Gettner P, Hale E, Collins M, Hensman A, et al. Impact of a physiologic definition on bronchopulmonary dysplasia rates. Pediatrics 2004;114(5):1305-1311.
60. Walsh MC, Yao Q, Horbar JD, Carpenter JH, Lee SK, Ohlsson A Changes in the use of postnatal steroids for bronchopulmonary dysplasia in 3 large neonatal networks. Pediatrics 2006;118(5):e13281335.

61. Walther FJ, Findlay RD, Durand M. Adrenal suppression and extubation rate after moderately early low-dose dexamethasone therapy in very preterm infants. Early Hum Dev 2003;74(1):37-45.

62. Doyle LW, Davis PG, Morley CJ, McPhee A, Carlin JB, DART Study Investigators. Low-dose dexamethasone facilitates extubation among chronically ventilator-dependent infants: a multicenter, international, randomized, controlled trial. Pediatrics 2006;117(1): 75-83.

63. Cotton RB, Stahlman MT, Bender HW, Graham TP, Catterton WZ, Kovar I. Randomized trial of early closure of symptomatic patent ductus arteriosus in small preterm infants. J Pediatr 1978;93(4):647-651.

64. Brown ER. Increased risk of bronchopulmonary dysplasia in infants with patent ductus arteriosus. J Pediatr 1979;95(5 Pt 2):865-866.

65. Clyman RI. Recommendations for the postnatal use of indomethacin: an analysis of four separate treatment strategies. J Pediatr 1996; 128(5 Pt 1):601-607.

This article is approved for Continuing Respiratory Care Education credit. For information and to obtain your CRCE

(free to AARC members) visit www.rcjournal.com

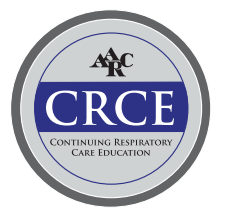

